\title{
Caracteres estructurales y ultraestructurales de la gametogénesis de Chara hydropitys (Charophyceae)
}

\author{
Edgar Javier Rincón-Baron ${ }^{1}$, Yenny Magaly Castrillón Bolaños², Gerardo Andrés Torres², \\ Fernando Alzate Guarin ${ }^{1} \&$ Silvia Espinosa Matías ${ }^{3}$
}

1. Grupo de Estudios Botánicos, Instituto de Biología, Universidad de Antioquia, calle 67 № 53 -108, Medellín, Colombia; edgar.rincon@udea.edu.co, ejrbaron@gmail.com

2. Unidad de Microscopía Electrónica, Carrera $2 \mathrm{~N}^{\circ} 1$ A-25, Urbanización Caldas, Universidad del Cauca, Popayán, Colombia; gantorres@gmail.com, magalycastrillon@gmail.com

3. Laboratorio de Microscopía Electrónica de Barrido, Facultad de Ciencias, Universidad Nacional Autónoma de México, Av. Universidad 3000, C.P. 04510, Ciudad de México, México; sem@unam.mx, semfc2010@gmail.com

$$
\text { Recibido 01-XII-2016. Corregido 28-VI-2017. Aceptado 27-VII-2017. }
$$

\begin{abstract}
Structural and ultrastructural characters of the gametogenesis of Chara hydropitys (Charophyceae). In Charophyceae, the oosporangia and antheridia are the respective female and male structures of sexual reproduction. These organs are characterized by their morphological complexity and usefulness in taxonomy and systematics. Here we described the structural and ultraestructural details of Chara hydropitys gametogenesis. The fertile material from the algae was collected in a tributary stream of the Río Meléndez in Cali, Colombia $\left(3^{\circ} 21^{\prime} 23^{\prime \prime} \mathrm{N}-76^{\circ} 32^{\prime} 5.2^{\prime \prime} \mathrm{W}\right)$ in March 2011. The specimens were fixed and processed following the standard protocols for inclusion in resin. Thin sections $(0.3-0.5 \mu \mathrm{m})$ were stained with toluidine $\mathrm{O}$, and were observed by photonic microscopy, and additional ultrathin sections $(60-90 \mathrm{~nm})$ were observed by transmission electron microscopy (TEM); other samples were processed and observed by scanning electron microscopy (SEM). We found that the oosporangia are covered with spiral cells, forming 10-12 convolutions and ends in five coronula cells. The immature oosporangia wall is formed by two layers that correspond to the wall of the spiral cells and to the oosphere. In mature stages, the oosporangia wall is composed by six additional layers, three of them are provided by the oosphere and the other three are provided by the spiral cells. Oosphere size increases progressively while the spiral cells grow and divide. The cytoplasm of the immature oosphere does not exhibit conspicuous cytoplasmic inclusions, nevertheless, with the maturation, the number of starch granules increases, occupying most of the cell volume. In the spiral cells of the mature oosporangia we observed large number of chloroplast with starch accumulations, between thylakoid lamellae and a vacuole that occupies almost the entire cell. By using SEM it was possible to appreciate, that the external wall of the oospore, more accurately, on the fossa area, shows verrucose micro-ornamentations with verrucae elevations. In mature antheridia, shield cells are strongly pigmented orange due to the presence of a large number of plastoglobules between thylakoid lamellae. The spermatogenous filaments are developed from cells of the secondary capitulum; those, by unidirectional and sincronic mitotic divisions develop the spermatocytes. The biflagellate antherozoids are developed from the haploid cells by spermiogenesis. The subcellular events related with these division and differentiation processes, include first, chromatin condensation, loss of nucleoli and more activity in dictyosomes. Subsequently, retracts the cytoplasm and the organelles are aligned along the condensed nucleus and flagellar apparatus. Mature antherozoids emerge through a side wall pore of the spermatocytes. All the described events showed that the gametogenesis processes and the gametes structural details in general, are widely conserved in this algae group. Rev. Biol. Trop. 65 (4): 1507-1526. Epub 2017 December 01.
\end{abstract}

Key words: antheridia, Chara, composed oosporangial wall, gametogenesis, oosporangia, ultrastructure. 
Las Charophyceae son consideradas como el grupo de algas más estrechamente relacionadas a las plantas terrestres (Karol, McCourt, Cimino, \& Delwiche, 2001; Turmel, Otis, \& Lemieux, 2006; McCourt, Delwiche, \& Karol, 2004), no obstante, en la actualidad su posición filogenética es controversial (Turmel et al., 2006; Lemieux, Otis, \& Turmel, 2007; Wodniok et al., 2011; Timme, Bachvaroff, \& Delwiche, 2012). Las Charophyceae es un grupo diverso de amplia distribución con aproximadamente 400 especies (Wood, 1964, 1965; Khan \& Sharma, 1984). Estas algas crecen como macrófitas sumergidas principalmente en ambientes lóticos y lénticos, cumpliendo varias funciones importantes en los ecosistemas dulceacuícolas (Coops, 2002). Adicionalmente, se las considera un buen indicador de la calidad del agua debido a que son muy sensibles a la contaminación (Van Dijk \& Van Vierssen, 1991; Coops, 2002; Cirujano, Murillo, Meco, \& Fernández, 2007; Schneider, 2007).

Las Charophyceae se caracterizan por la complejidad de su morfología vegetativa y reproductiva, lo cual hace que su taxonomía sea compleja y difícil de discernir (van den Hoek, Mann, \& Jahns, 1995; Graham, Wilcox, \& Graham, 2009; Bueno, Bicudo, Biolo, \& Meurer, 2009; Urbaniak, 2011; Sato, Sakayama, Sato, Ito, \& Sekimoto, 2014; Schneider, Rodrigues, Moe, \& Ballot, 2015). Tradicionalmente se han utilizado caracteres morfológicos vegetativos y reproductivos macro y micro-estructurales en su taxonomía (Wood \& Imahori, 1965; Proctor, 1971; Bueno et al., 2009; Bueno, Prado, Meurer, \& Bicudo, 2011; Graham et al., 2009; Lee, 2008; Sakayama, 2008; Sato et al., 2014). En este sentido, los patrones ultraestructurales presentes en la pared de la oospora, son considerandos cruciales para la circunscripción de las especies (John, Moore, \& Green, 1990; Leitch, John, \& Moore, 1990; Casanova, 1991, 1997; Ray, Pekkari, \& Snoeijs, 2001; Sakayama et al., 2005; Urbaniak, 2011). Lo anterior se relaciona con la naturaleza conservada de estos caracteres, que al parecer están principalmente influenciados por la genética y no por factores externos o de desarrollo, siendo así, excelentes marcadores taxonómicos (Ray et al., 2001; Urbaniak, 2011; Schneider et al., 2015). Así mismo, algunos autores consideran que en Charophyceae, los caracteres vegetativos son fenotípicamente muy plásticos, y se debe tener cuidado al utilizarlos como referente taxonómico, ya que, hasta el momento, son pocos los trabajos que muestran el intervalo de variación de los mismos ante factores externos (Schneider et al., 2015). Estos mismos autores, indican que incluso se puede presentar variaciones en las estructuras vegetativas en organismos con estrecha relación filogenética y que podría corresponder más a variedades que a especies propiamente dichas.

En la actualidad, el género Chara L. está representado por aproximadamente 120 especies de amplia distribución que ocupan un amplio rango de hábitats (Beilby \& Casanova, 2014; Arora \& Sahoo, 2015). Chara hydropitys Reich. es una especie cosmopolita (John et al., 1990; Krishnan, 2006; Bueno et al., 2011; Meurer \& Bueno, 2012) que se puede diferenciar de especies afines como Chara fibrosa $\mathrm{C}$. Agardh ex A. Bruzelius y Chara gymnopitys A. Braun especialmente por la ornamentación de la pared de la oospora y por análisis de isoenzimas (Krishnan, 2006).

La reproducción sexual en las Charophyceae es oogámica, es decir, se debe a estructuras sexuales complejas y especializadas conocidas como gametangios, distinguibles por su morfología y tamaño. Estos son de dos tipos: los masculinos, conocidos como anteridios donde se desarrollan gran cantidad de anterozoides biflagelados de forma helicoidal; y los femeninos u oosporangios, que cuentan con una ovocélula u oosfera. Ambos gametangios poseen células estériles conocidas como células escuderas que los rodean y protegen (Pickett-Heaps, 1968; John et al., 1990; Leitch et al., 1990; Graham et al., 2009; Lee, 2008; Sakayama, 2008; Sato et al., 2014). A pesar de que la microarquitectura de la pared externa de la oosfera reviste gran importancia taxonómica, sistemática y evolutiva, son escasos los trabajos encontrados en la literatura científica encaminados a describir la variabilidad de estos 
patrones (John et al., 1990; Leitch et al., 1990; Casanova, 1991, 1997; Ray et al., 2001; Blume, Blindow, Dahlke, \& Vedder, 2009; Urbaniak, 2011, Schneider et al., 2015). Algunos autores también han indicado que la microestructura interna de la pared oosporangial compuesta (POC) podría aportar datos importantes para el entendimiento de la biología reproductiva y sistemática de las Charophyceae en general (Leitch, 1986,1989; John \& Moore, 1987; Leitch, 1989; Leitch et al., 1990; Sakayama et al., 2005). La POC es una estructura multilaminar constituida por ocho capas, que se deposita simultáneamente a partir de la oospora y las células escuderas. Estas capas se pueden reconocer por su estructura y electrodensidad usando MET (Leitch, 1986, 1989; Leitch et al., 1990). Su función al parecer se relaciona con la protección de la oospora hasta su germinación, principalmente, cuando las condiciones externas no son las apropiadas (Leitch, 1989; Kalin \& Smith, 2007).

En relación al desarrollo y estructura de los anteridios, así como de la espermatogénesis y espermiogénesis en Charophyceae, es notable también la falta de información, y aunque los trabajos que existen son detallados y cuentan con excelentes descripciones, están restringidos solo a unas cuantas especies. Así, Pickett-Heaps (1968) describió de forma pormenorizada el desarrollo y estructura del anteridio y el proceso de espermatogénesis y espermiogénesis en Chara fibrosa. Posteriormente, Moestrup (1970), Cocucci y Cáceres, (1976) y Kwiatkowska y Maszewski (1986) describen estos mismos procesos en Chara corallina Klein ex C.L. Willdenow, Chara contraria A. Braun ex Kützing y Chara vulgaris L., respectivamente. Duncan, Renzaglia y Garbary (1997) completan y detallan la ultraestructura de $C$. vulgaris e indican la relación intragenérica de estos caracteres en Charophyceae y con otros grupos relacionados de algas. Más recientemente, la estructura del anterozoide maduro de Nitella hialina (De Candolle) C. Agardh, fue descrita por Vouilloud, Cáceres y Leonardi (2010). En este trabajo, los autores encontraron diferencias en la disposición ultraestructural de los orgánulos en torno a las raíces microtubulares, en especial de las mitocondrias, al compararlos con los anterozoides de Chara. Posteriormente, estos mismos autores describieron los eventos subcelulares relacionados con los procesos de división y diferenciación celular para la formación de los espermatocitos y anterozoides en Chara contraria var. nitelloides, incluyendo detalles importantes de la dinámica de los microtúbulos y las raíces microtubulares (Vouilloud, Leonardi, \& Cáceres, 2012).

Los objetivos de esta investigación fueron obtener datos relevantes y originales sobre la biología reproductiva y estructura de los gametangios de Charophyceae, en particular de la especie $C$. hydropitys. Se detallan algunos aspectos de la ontogenia de los oosporangios, así como el depósito y ultraestructura de la POC y la organización de las células espirales y las coronulares. Finalmente, se describe la estructura de los anteridios maduros y los procesos subcelulares relacionados con la espermatogénesis y espermiogénesis, que se dan al interior de los filamentos anteridiales de esta especie.

\section{MATERIALES Y MÉTODOS}

Las muestras de $C$. hydropitys se tomaron en recipientes plásticos separándolas manualmente de los sustratos a los cuales de adhieren. La recolección del material se hizo durante marzo de 2011 en una quebrada tributaria al Río Meléndez, localizada a $3^{\circ} 21^{\prime} 23^{\prime \prime} \mathrm{N}$ \& $76^{\circ} 32^{\prime} 5.2^{\prime \prime} \mathrm{W}$ a 995 m.s.n.m. en el área metropolitana de la ciudad de Cali, departamento del Valle del Cauca, Colombia. En total se tomaron 30 talos con oosporangios y anteridios en diferentes momentos de maduración. La especie $C$. hydropitys se identificó con la ayuda bibliografía especializada para el grupo (Wood, 1964, 1965; Wood \& Imahori, 1965; Haas, 1994; Krishnan, 2006; De Winton, Dugdale, \& Clayton, 2007; Meurer, Biolo, Bortolini, \& Bueno, 2008; Bueno et al., 2009; Bueno et al., 2011; Urbaniak, 2011). El ejemplar de la especie $C$. hydropitys se depositó el herbario de la Universidad del Cauca (CAUP), Rincón 020. 
Para la observación de las muestras en cada una de las técnicas de microscopía utilizadas, se tomaron 30 oosporangios y 30 anteridios en diferentes momentos de maduración. Los oosporangios y anteridios de $C$. hydropitys para microscopía fotónica y electrónica, se procesaron de acuerdo a protocolos estándar para material vegetal (Bozzola \& Russell, 1998). La fijación de muestras por 24 horas se realizó en glutaraldehído al $2.5 \%$ en buffer fosfato $0.2 \mathrm{M}$ (pH 7.2). Una vez fijado el material se lavó tres veces con buffer fosfato al $0.2 \mathrm{M}(\mathrm{pH}$ 7.2) por un periodo de $30 \mathrm{~min}$. Posteriormente, se postfijó en Tetróxido de Osmio (OsO4) al $2 \%$ en Ferrocianuro de Potasio (C6N6FeK4) al $1.5 \%$ durante 4 horas en la oscuridad, con agitación constante y a $4{ }^{\circ} \mathrm{C}$. Posteriormente, el material postfijado se lavó en el mismo buffer por 40 min y se deshidrató en series de acetona en orden ascendente $(10,30,50,70,90,95$ y $100 \%$ ) para continuar con la imbibición de las muestras en mezclas de acetona/resina Spurr ${ }^{\circledR}$ (Spurr, 1969) mediante goteo (1 gota de resina cada $10 \mathrm{~min}$.) hasta alcanzar una proporción de 1:3 en un tiempo de 12 horas. Finalmente, se realizaron tres cambios en resina pura por 48 horas, a temperatura ambiente y con agitación constante. La polimerización de la resina se realizó a $70{ }^{\circ} \mathrm{C}$ por 48 horas. Los cortes semifinos de $0.3-0.5 \mu \mathrm{m}$ se obtuvieron en Ultramicrótomo (Ultracut UCT-Leica); luego fueron teñidos con azul de toluidina por $30-40$ s. Las observaciones se realizaron con un microscopio fotónico (Nikon 80i Eclipse) equipado con contraste diferencial de interferencia (CDI). Las fotografías se obtuvieron con cámara digital Nikon DS- $2 \mathrm{MV} ®$, utilizando el programa NIS Elements versión 3.07 de Nikon. El procesamiento de las imágenes se llevó a cabo con el programa Imagen-Pro Analyzer 6.3 de Media Cybernetics.

Para el procesamiento de las muestras en MET, los oosporangios y anteridios de $C$. hydropitys se procesaron de acuerdo al protocolo propuesto por Bozzola y Russell (1998) anteriormente descrito. Las secciones ultrafinas de $60-90 \mathrm{~nm}$ se obtuvieron con cuchilla de diamante y se contrastaron con acetato de uranilo (40 min) y citrato de plomo (15 min.). En total se observaron 90 secciones con un microscopio electrónico de transmisión JEOL JEM-1011. Finalmente, las muestras para MEB se fijaron en glutaraldehido al $2.5 \%$ y buffer fosfato $0.2 \mathrm{M}(\mathrm{pH} 7.2)$ por 24 horas y se deshidrataron en una serie creciente de etanol (10, $30,50,70,90,95$ y $100 \%$ ). Luego se efectuó el secado a punto crítico con un desecador SAMDRI ${ }^{\circledR}-795$. Los talos se colocaron en una cinta de carbono conductiva de doble cara y se recubrieron con oro en un ionizador Denton Vacuum Desk IV durante $5 \mathrm{~min}$. Las observaciones de hicieron en un microscopio electrónico de barrido JEOL JSM-6490LV. En el caso de los oosporangios, unos se fotografiaron completos y a otros se les retiró mecánicamente las células espirales, para la observación de la morfología de las oosporas.

Los términos utilizados para la descripción de la estructura y desarrollo de los oosporangios y oosporas se tomaron sensu Leitch (1989) y Leitch et al., (1990). Para la ornamentación de la pared de la oospora se usaron los términos sensu John \& Moore (1987) y John et al., (1990). Mientras que los términos utilizados para la descripción de la estructura y desarrollo de los anteridios se tomaron sensu Vouilloud et al., (2012). Para la obtención de las medidas se tomó un $n=30$ y están representadas por el promedio de las mismas y en algunos casos se presenta la desviación estándar.

\section{RESULTADOS}

Oosporangios: $C$. hydropitys es un alga dulceacuícola monoica que presenta en los nodos de las ramas apicales gran número de gametangios masculinos y femeninos, siendo estos escasos en los nodos de las ramas laterales. Los oosporangios se ubican en la parte superior del nudo y son protegidos por cuatro brácteas. Generalmente, cada oosporangio se encuentra acompañado por uno o dos anteridios que se reconocen por su color naranja y se sitúan inmediatamente bajo el oosporangio (Fig. 1A). El talo tiene cortex triplóstico, las estípulas forman una fila y de corticación 

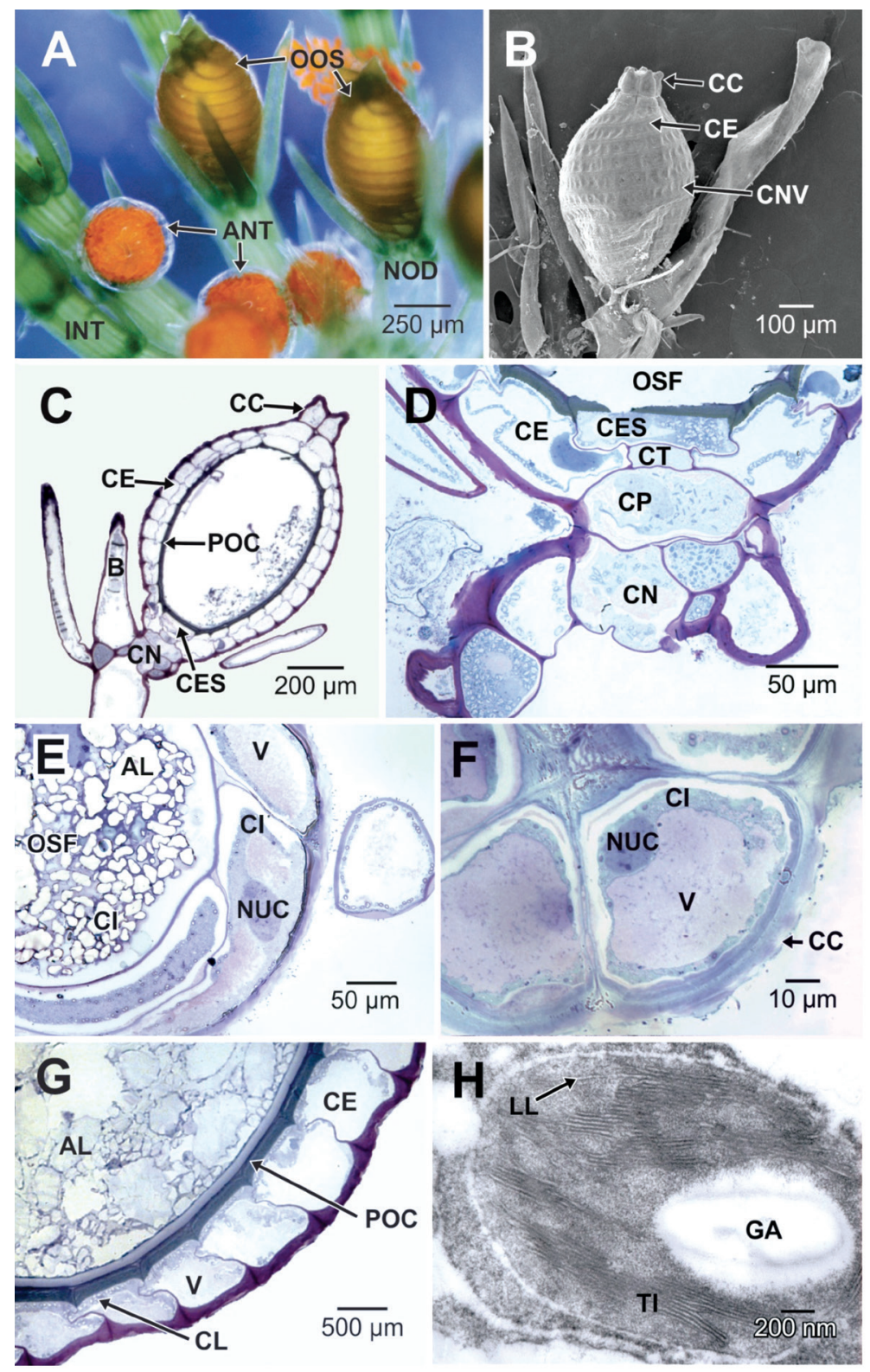

Fig. 1. A-H. Gametangios de Chara hydropitys. A. Oosporangios y anteridios maduros en la región nodal del talo. B. Detalle del oosporangio. C. Oosporangio maduro en sección longitudinal. Se aprecian las células coronulares, espirales, oospora, la célula estéril, pedicular y la nodal. D. Acercamiento a la zona de unión entre el oosporangio y la región nodal. E. Corte transversal del oosporangio inmaduro, se aprecia la oospora y las células espirales. F. Corte transversal de las células coronulares. G. Detalle del oosporangio maduro en sección longitudinal se aprecian la oospora las células espirales y la pared oosporongial compuesta (POC). H. Detalle de los cloroplastos presentes en las células espirales. Se aprecian gránulos de almidón entre los tilacoides.

AL: almidón; ANT: anteridios; $\mathrm{B}$ : bráctea; $\mathrm{CC}$ : células coronulares; CE: células espirales; CES: célula estéril del oosporangio; CI: citoplasma; CL: cloroplastos; $\mathrm{CN}$ : célula nodal; CNV: circunvoluciones; $\mathrm{CP}$ : célula pedicelar; CT: célula central de la oospora; GA: granulo de almidón; INT: internodos; LL: laminillas tilacoidales libres; NOD: nodos; NUC: núcleo; OSF: oospora; OOS: oosporangio; POC: pared oosporangial compuesta; TI: tilacoides; V: vacuolas.

Fig. 1. A-H. Gametangia of Chara hydropitys. A. Oosporangia and mature anteridia in the nodal region of the thallus. B. Details of the Oosporangium. C. Longitudinal

section of a mature oosporangium. The coronula cells, spiral cells, oospora, sterile cells, pedicelar and nodal cells are evident. D. Close up of the union area between oosporangium and the nodal region. E. Transversal section of an immature oosporangium, showing the oospora and spiral cells. F. Transversal section of the coronula cells. G. Longitudinal section of oosporangium, oospora, spiral cells and compound oosporongial wall (COW). H. Close up of chloroplasts observed into spiral cells. Starch granules among the thylakoids are observed.

AL: starch; ANT: antheridia; B: bract; CC: coronula cells; CE: spiral cells; CES: sterile oosporangium cell; CI: cytoplasm; CL: chloroplasts; CN: nodal cell; CNV: circumvolutions; CP: pedicelar cell; CT: central oospora cell; GA: starch granule; INT: internodes; LL: free lamellae thylakoids; NOD: nodes; NUC: nucleus; OSF: oospora; OOS: oosporangium; POC: compound oosporangial wall; TI: thylakoids; V: vacuoles. 
irregular y no presente en la totalidad de las ramas. El oosporangio maduro es una estructura de contorno ovalado con una longitud promedio de $681.74 \pm 56.45 \mu \mathrm{m}$ y un diámetro promedio de $470.30 \pm 37.85 \mu \mathrm{m}$. Esta estructura está conformada por las células espirales que se disponen de forma helicoidal alrededor de la oosfera hasta la zona apical, donde se encuentran con las células coronulares (Fig. 1A y Fig. 1B). Durante todo el desarrollo, las células espirales y las coronulares son translúcidas. Por el contrario, la oosfera es de color amarillento en estado inmaduro, tornándose de color negro al alcanzar la madurez. El oosporangio maduro cuenta además con tres células dispuestas en la parte inferior; la primera situada inmediatamente debajo de la oosfera y corresponde a la célula estéril, que junto con las células espirales se conocen como células escuderas. Seguida de la célula central y finalmente unida al eje del talo a través de las células nodales, encontramos la célula pedicelar (Fig. 1C y Fig. 1D).

Tanto las células espirales como las coronulares presentan una enorme vacuola central rodeada por citoplasma de aspecto granular (Fig. 1E y Fig. 1F). En el citoplasma, y en posición parietal en relación a la pared celular de estos dos tipos de células, se ubican abundantes cloroplastos ovalados que presentan por lo general uno o dos prominentes gránulos de almidón (Fig. 1G y Fig. 1H). Los grana están formados por más de cinco membranas tilacoidales apiladas y membranas tilacoidales individuales que las interconectan, distribuidas en un amplio estroma cloroplastídico (Fig. 1H).

La oosfera madura es una célula con contorno ovado que se ubica en la zona central del oosporangio y ocupa la mayor parte del volumen de esta estructura (Fig. 2A). El núcleo de la oosfera se localiza en la parte basal y está rodeado por numerosos gránulos de almidón (Fig. 2B). Las células espirales y las coronulares presentan paredes anticlinales o tangenciales externas gruesas y de aspecto multilaminar. En tanto que las paredes periclinales o radiales son delgadas, y se conectan internamente con el borde espiral o ribbon que se origina a partir de las paredes anticlinales internas de esta misma estructura (Fig. 2A, Fig. 2C y Fig. 2D).

Los oosporangios inician su desarrollo a partir de células del nudo que también originan los anteridios. La célula inicial que formará el oosporangio se divide por mitosis unidireccional originando tres células: la célula apical, que posteriormente se diferenciará en la célula madre de la oosfera. La cual se divide para formar la oospora y la célula estéril. Luego encontramos la célula central que experimenta una serie de divisiones mitóticas, que dan lugar a la formación de las células espirales, quienes, a su vez, formarán las cinco células coronulares. Finalmente, la célula basal, que dará origen a la célula pedicelar del oosporangio (Fig. 2E y Fig. 2F).

Antes de la fertilización, la oosfera solo está recubierta por dos paredes primarias, una derivada de la misma oosfera y la otra de las células espirales (Fig. 2G). Al mismo tiempo que se lleva a cabo la fecundación, se inicia el depósito de la pared oosporongial compuesta (POC), generada de manera simultánea por las células espirales y la oospora, al terminar la síntesis de esta pared, se deposita una capa calcificada (Fig. 2H).

La POC madura queda finalmente formada por ocho capas que se distinguen por su estructura, grosor y electrodensidad. Las capas formadas a partir de las células espirales en orden de depósito son: pared primaria de las células espirales, capa cristalina, capa helicoidal pigmentada y capa de microornamentación. Las capas formadas a partir de la oospora son: pared primaria de la oospora, capa amorfa, capa helicoidal de la oospora y capa microfibrilar (Fig. 3A, Fig. 3B).

La capa de microornamentación mide en promedio $0.23 \mu \mathrm{m}$ de grosor es una capa electrodensa que se caracteriza por tener ornamentación verrucada, con papilas de forma cónica en diferentes momentos de maduración, las más desarrolladas miden cerca de $0.5 \mu \mathrm{m}$ de longitud y tienen un poro apical central que se extiende hasta la base de la papila; las papilas menos desarrolladas carecen de poro y pueden o no fusionarse (Fig. 3A). La capa helicoidal 
Fig. 2. A-H. Oosporangio maduro y su desarrollo de Chara hydropitys. A. Detalle de un oosporangio con la oospora madura, se aprecia el engrosamiento diferencial de la pared oosporangial compuesta y las células coronulares y espirales. B. Detalle del núcleo de la oospora rodeado por gránulos de almidón. C. Detalle de las células coronulares, con una vacuola que ocupa la mayor parte del citoplasma, las paredes anticlinales son más engrosadas. D. Células espirales con paredes anticlinales externas engrosadas y paredes periclinales delgadas. Se aprecia la pared oosporangial compuesta y el borde espiral. E. Oosporangio inmaduro, se han formado: la célula madre de la oospora, la célula central y las células espirales, mientras que las células coronulares han iniciado su desarrollo. Note que la célula estéril aún no se ha formado. F. Siguiente etapa del desarrollo del oosporangio. Se observa a la oospora con abundante contenido de almidón. Se ha formado la célula estéril, y permanecen la célula central y pedicelar. G. Detalle del oosporangio inmaduro mostrando las dos paredes primarias que cubren a la oospora. H. Acercamiento a la pared compuesta del oosporangio. Note la capa calcificada en las células espirales.

AL: almidón; B: bráctea; $\mathrm{BE}$ : borde espiral; CA: capa calcificada; CC: células coronulares; CL: cloroplastos; CE: células espirales; CES: célula estéril del oosporangio; CMO: célula madre de la oospora; $\mathrm{CN}$ : célula nodal; $\mathrm{CP}$ : célula pedicelar; $\mathrm{CT}$ : célula central de la oospora; NUC: núcleo; OSF: oospora; PA: pared anticlinal; POC: pared oosporangial compuesta; PP: Pared periclinal; PPC: pared primaria de las células espirales; PPO: pared primaria de la oospora; V: vacuolas.

Fig. 2. A-H. Mature oosporangium of Chara hydropitys and its development. A. Detail of an oosporangium with mature oospora; note the differential thickening of the compound oosporangial wall. Coronula and spiral cells are shown. B. Nucleus of the oospora surrounded by starch granules. C. Coronula cells

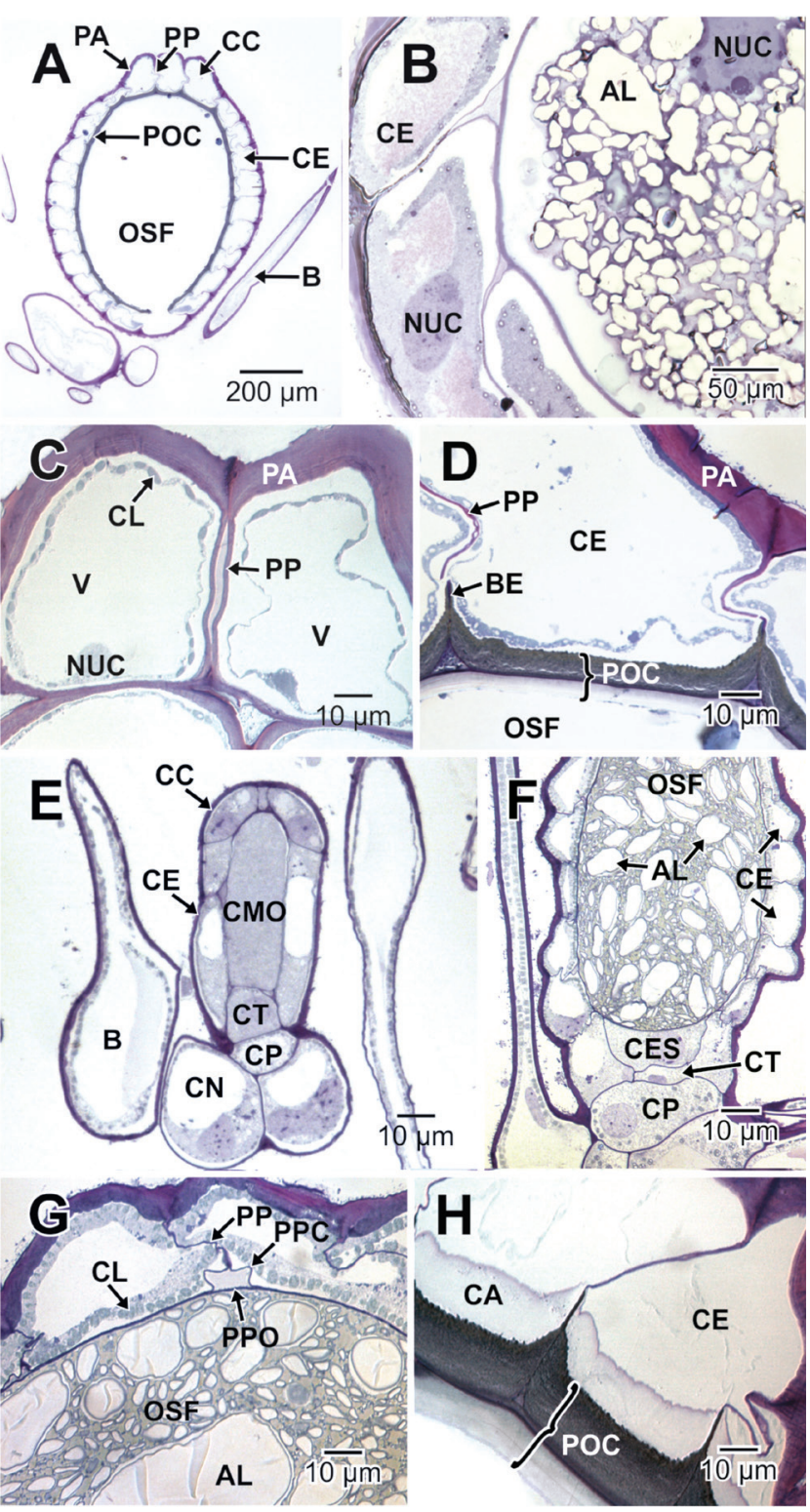
with a vacuole, which occupies most of the cytoplasm; note that anticlinal walls are thicker. D. Spiral cells with external thickened anticlinal walls and thin periclinal walls. The compound oosporangial wall and spiral border are observed. E. Immature oosporangium, these structures have been development the: oospora mother cell, central cell and spiral cells, whereas, coronula cells have initiated its development. The sterile cell has not developed even. F. Next stage of development of oosporangium: note the oospora with abundant content of starch. The sterile cell has been development, and the central and pedicel cell remains. G. Immature oosporangium showing two primary walls covering the oospora. H. Close up of compound oosporangium wall. The calcified layer in the spiral cells is present.

AL: starch; B: bract; BE: spiral border; CA: calcified layer; CC: coronula cells; CL: chloroplasts; CT: oospora central cell; CE: spiral cells; CES: sterile oosporangium cell; CMO: oospora mother cell; CN: nodal cell; CP: pedicel cell; NUC: nucleus; OSF: oospora; PA: anticlinal wall; POC: compound oosporangial wall; PP: periclinal wall; PPC: spiral cells primary wall; PPO: oospora primary wall; V: vacuoles. 


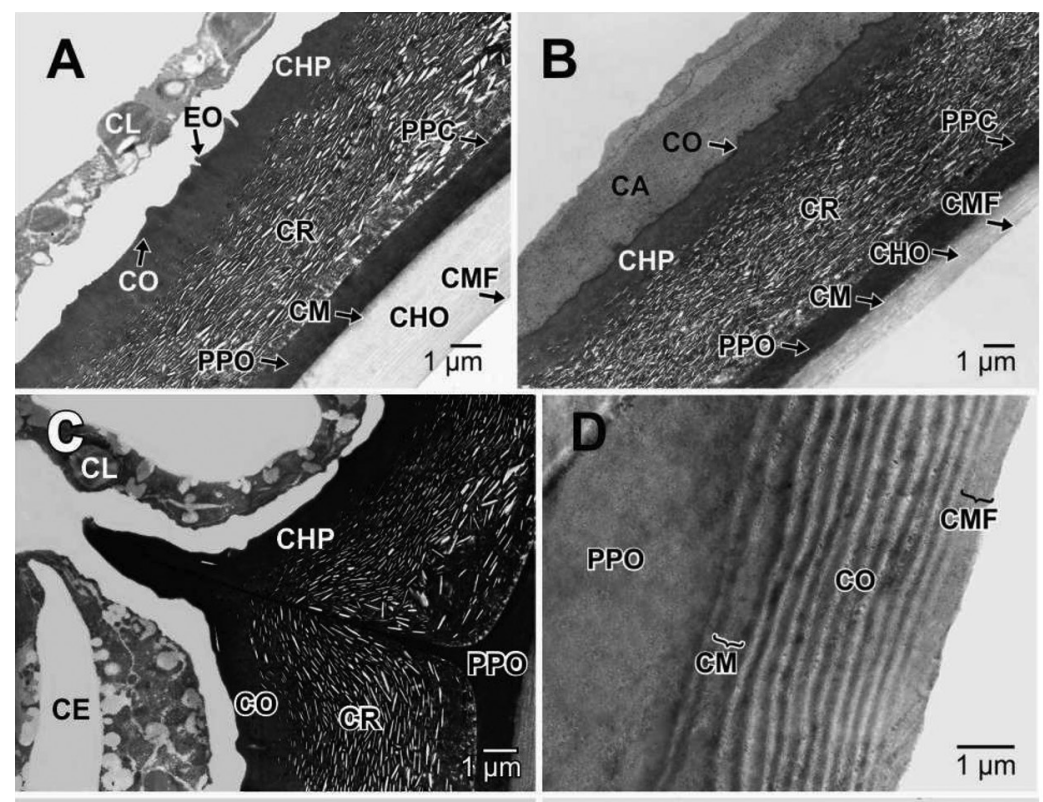

Fig. 3 A-H. Ultrastructura de la pared oosporangial compuesta madura y capa calcificada de Chara. hydropitys. A-B. Se muestran las ocho capas que conforman la pared oosporangial compuesta, las cuales se diferencian en ultraestruc-
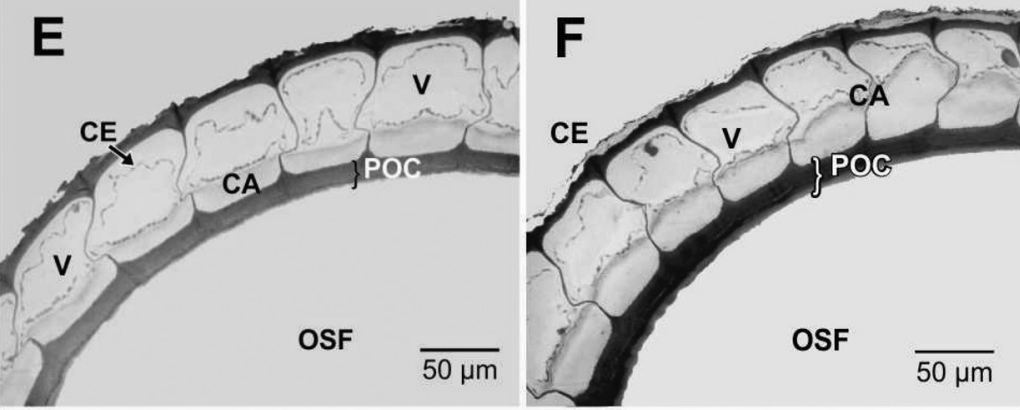
tura y electrodensidad. C-D. Detalle de la pared oosporangial compuesta, donde se pueden apreciar las capas secretadas por las células espirales y la oospora respectivamente. E-F. Muestran el progresivo depósito de la capa calcificada. G. Detalle de la capa calcificada mostrando la ectocalcina y la endocalcina. H. Espacios intercelulares en la pared oosporangial compuesta.

CA: capa calcificada; $\mathrm{CE}$ : células espirales; $\mathrm{CO}$ : capa de ornamentación; CHO: capa helicoidal de la oospora; CHP: capa helicoidal pigmentada; CL: cloroplastos; CM: capa amorfa; CMF: capa microfibrilar; $\mathrm{CR}$ : capa cristalina; EC: ectocalcina;

EI: espacio intercelular; EN: endocalcina; EO: papilas con poro; OSF: oospora; POC: pared oosporangial compuesta; PPC: pared primaria de las células espirales; PPO: pared primaria de la oospora; V: vacuolas.

Fig. 3 A-H. Ultrastructure of mature compound oosporangial wall and utrastructure of calcified layer of Chara hydropitys. A-B. Note the compound oosporangial wall formed by eight layers that differ in ultrastructure and electrodensity. C-D. Close up of the compound oosporangial wall. The layers secreted by spiral cells and oospora can be seen respectively. E-F. Progressive deposition of calcified layer is shown. G. Detail of a calcified layer showing ectocalcine and endocalcine. H. Intercellular spaces in the compound oosporangial wall are shown.

CA: calcified layer; CE: spiral cells; CO: layer of ornamentation; CHO: oospora helicoidallayer; CHP: pigmented helicoidal layer; CL: chloroplasts; CM: amorphous layer; CMF: microfibrillar layer; CR: crystalline layer; EC: ectocalcine; EI: intercellular space; EN: endocalcine; EO: papilla with pore; OSF: oospora; POC: compound oosporangial wall; PPC: spiral cells primary wall; PPO: oospora primary wall; V: vacuoles. 
pigmentada tiene en promedio $1.23 \mu \mathrm{m}$ de grosor, es una capa electrodensa que presenta microfibrillas orientadas en forma helicoidal. Esta capa en ocasiones es difícil de visualizar (Fig. 3A y Fig. 3B). La capa cristalina mide en promedio $4.9 \mu \mathrm{m}$ de grosor, también es electrodensa y contiene cristales no electrodensos en forma de bastón densamente apretados y orientados en la misma dirección. En la cara interna de esta capa, y limitando con la pared primaria de la oospora, se observa una matriz en la cual los cristales de menor tamaño se disponen de manera irregular (Fig. 3B).

La pared primaria de las células espirales está inmediatamente bajo la capa cristalina, mide en promedio $0.38 \mu \mathrm{m}$ de grosor, presenta límites bien definidos, es marcadamente electrodensa y homogénea (Fig. 3B y Fig. 3C). Debajo de la capa de la pared primaria de las células espirales, se localiza la pared primaria de la oosfera que es más engrosada, pero con características similares de electrodensidad (Fig. 3B y Fig. 3C). La capa amorfa se localiza debajo de la pared primaria de la oosfera es delgada y un poco menos electrodensa que la anterior (Fig. 3B y Fig. 3C). Posteriormente, encontramos la capa helicoidal de la oospora, la cual mide en promedio $1.35 \mu \mathrm{m}$ y se caracteriza por presentar microfibrillas de apariencia ondulada y paralelas entre sí, dándole apariencia multilaminar. Estas láminas están constituidas por materiales de mayor y menor electrodensidad intercaladas unas con otras. La última capa derivada de la oospora es la capa microfibrilar que es la de menor grosor (0.33 $\mu \mathrm{m}$ promedio) y es homogéneamente electrodensa (Fig. 3B y Fig. 3D). Esta capa se encuentra en contacto con la membrana celular y el citoplasma de la oosfera.

Posterior a la diferenciación de la POC, las células espirales forman una capa calcificada, mediante la fijación progresiva de carbonato de calcio y magnesio que se depositan sobre la capa de microornamentación. La capa calcificada inicialmente adopta una forma cóncava y a medida que se engrosa y desarrolla se torna convexa (Fig. 3E y Fig. 3F). Con el depósito de esta capa, el citoplasma de las células espirales se va reduciendo. En C. hydropitys, la capa calcificada posee una matriz orgánica de aspecto microgranular; con microgránulos electrodensos de mayor tamaño, así como, otros menos electrodensos más pequeños alrededor de las microfibrillas que se disponen de forma casi paralelas (Fig. 3G). Al final del depósito de esta capa se pueden distinguir débilmente dos zonas, una interna más electrodensa que corresponde a la endocalcina que presenta mayor cantidad de gránulos electrodensos y otra externa menos electrodensa y sin microfibrillas y con pocos gránulos, denominada ectocalcina (Fig. 3G). Entre la pared primaria de las células escuderas y la pared primaria de la oospora se forman espacios intercelulares por lo general de contorno triangular que se llenan de material denso durante el desarrollo de la POC (Fig. 3H).

En las observaciones hechas con MEB se puede apreciar que la oospora de $C$. hydropitys tiene entre 11-12 circunvoluciones (Fig. 4A). La longitud y diámetro promedio de la oospora es $484.19 \mu \mathrm{m}$ y $347.76 \mu \mathrm{m}$, respectivamente; además posee entre 10-11(12) bordes espirales poco prolongados que surgen de un polígono formado por las células escuderas en la parte inferior del oosporangio. Posteriormente, estas células ascienden en sentido dextrógiro hasta encontrarse en la parte superior de forma excéntrica (Fig. 4A y Fig. 3B). La zona de fosa corresponde al espacio que se encuentra entre cada borde espiral, presenta ornamentación del tipo verrucado con papilas en diferentes etapas de formación (Fig. 4C y Fig. 3D). Las papilas más desarrolladas tienen un poro apical central, mientras que las otras se encuentran fusionadas o solitarias y sin poro. Se observaron de 30 a 34 papilas que atraviesan la fosa, es decir, entre cada borde espiral distribuidas de manera irregular (Fig. 4C y Fig. 4D). La microornamentación se extiende hasta los bordes espirales.

Los anteridios: Estas estructuras se desarrollan primero que los oosporangios y por lo general, ambos gametangios están asociados en los mismos nodos en cuyo caso siempre se localizan en la parte basal de los mismos 

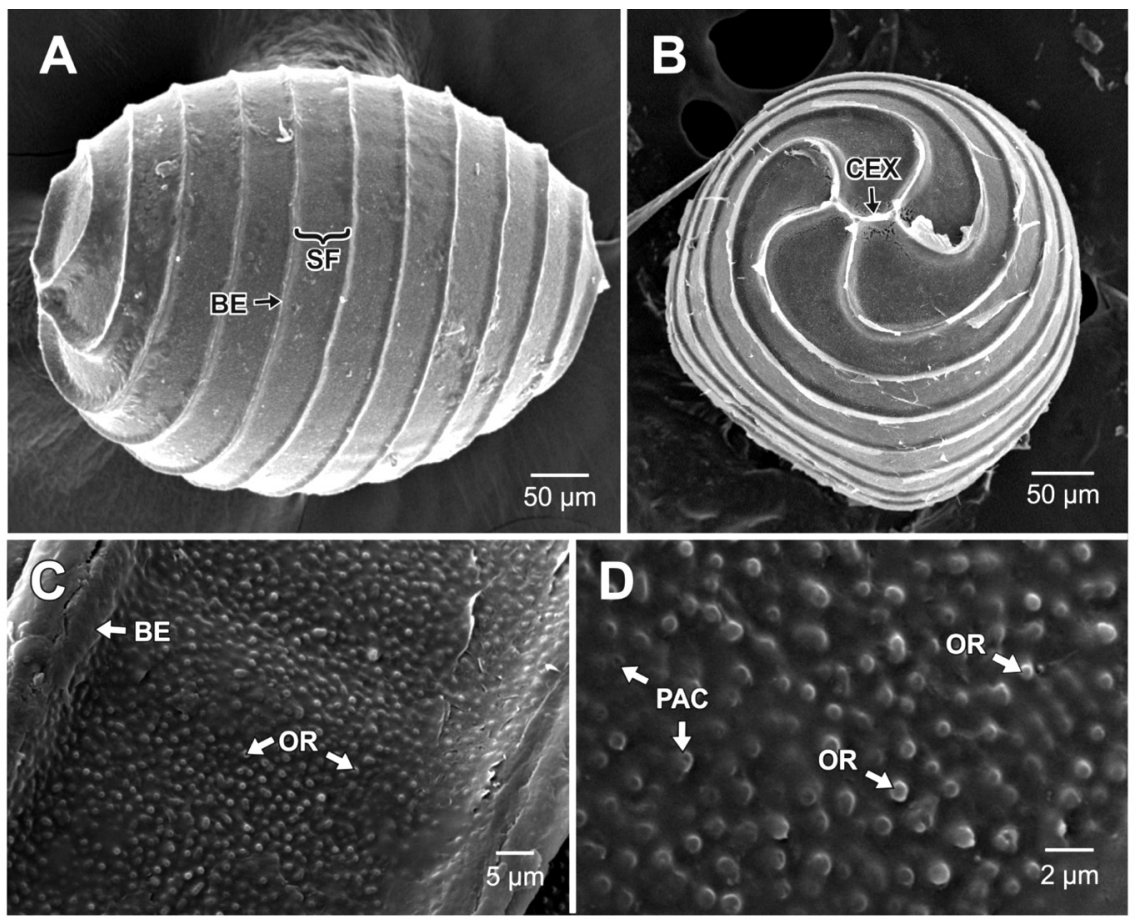

Fig. 4. A-D. Detalles ultraestructurales de la oospora y microornamentación de Chara hydropitys. A-B. Se aprecian las circunvoluciones y el ápice excéntrico de la oospora. C. Vista de la fosa y la capa de microornamentación de apariencia verrucada. D. Se aprecian papilas con poros.

BE: borde espiral; CEX: ápice excéntrico de la oospora; OR: microornamentación; PAC: papilas con poros; SF: fosa.

Fig. 4. A-D. Ultrastructure and microornamentation of the oospora of Chara hydropitys. A-B. The circumvolutions and the eccentric apex of the oospora are shown. C. View of fossa and the micro ornamentation layer; note the verrucate appearance. D. Close up of papillae with pores.

BE: spiral border; CEX: eccentric apex of the oospora; OR: micro ornamentation; PAC: papillae with pores; SF: fossa.

(Fig. 1A). Los anteridios son órganos de forma globular que están rodeados por ocho células escuderas (Fig. 5A). Estas células se unen a las células columnares conocidas como manubrios; éstos, se asocian con las células internas que forman el capítulo primario y secundario. Las células del capítulo secundario formarán los filamentos anteridiales (Fig. 5B). Cada una de estas células forma, por espermatogénesis y espermiogénesis, un anterozoide biflagelado, uninucleado y con forma helicoidal (Fig. 5C y Fig. 5D). En los anteridios maduros las células escuderas están fuertemente pigmentadas de color naranja por la presencia de numerosos plastoglóbulos asociados a los tilacoides (Fig. 5E y Fig. 5F).
Los filamentos anteridiales se dividen mitóticamente de forma unidireccional y sincrónica, con lo cual el anteridio aumenta de tamaño. Estas células espermatógenas son cortas con citoplasma escaso de apariencia granular y con varias vacuolas pequeñas (Fig. 6A y Fig. 6B). El núcleo es de contorno redondeado en posición central con cromatina de apariencia granular dispersa y presenta uno o dos nucléolos bien definidos (Fig. 6A y Fig. 6B). Las células del tejido espematógeno al interior de los filamentos anteridiales se diferenciarán en los espermatocitos para el momento en que cesan las divisiones celulares. Los espermatocitos en los filamentos anteridiales se aprecian de contorno rectangular ya que las células 

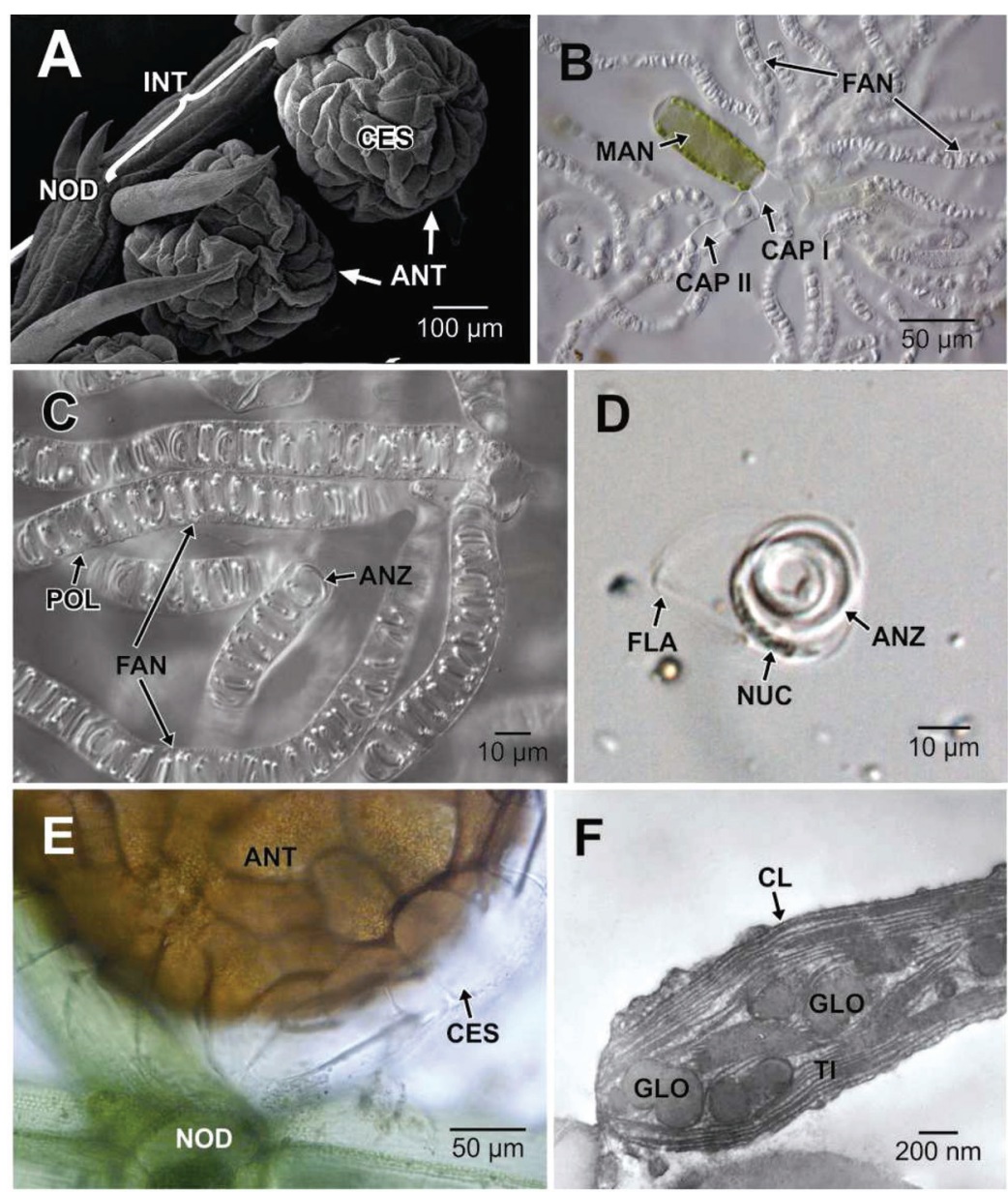

Fig. 5. A-F. Anteridios, anterozoides y cloroplastos de las células escuderas maduras de Chara hydropitys. A. Anteridios maduros unidos a los nodos de los talos. Se aprecian las células escuderas. B. Morfología interna de un anteridio. Se observan los manubrios, las células del capítulo primario y secundario, y los filamentos anteridiales. C. Se muestran los filamentos anteridiales al término de la espermiogénesis. Se observan anterozoides maduros y se detallan los poros laterales. D. Anterozoide, se observa: la región ocupada por el núcleo y los flagelos. E. Anteridio maduro con células escuderas mostrando el característico color naranja de éstas. F. Detalle de los cloroplastos de las células escuderas maduras.

ANT: anteridios; ANZ: anterozoides; CAP I: capítulo primario; CAP II: capítulo secundario; CES: células escuderas; CL: cloroplastos; FAN: filamentos anteridiales; FLA: flagelos; GLO: plastoglóbulos; INT: internodos; MAN: manubrio; NOD; nodos; NUC: núcleo. POL: Poro de liberación; TI: tilacoides.

Fig. 5. A-F. Antheridia, antherozoids and chloroplasts of shield mature cells of Chara hydropitys. A. Mature antheridia attached to the nodal region of the thallus; shield cells are evident. B. Internal morphology of the antheridium. Note the manubria, primary and secondary capitular cells and antheridial filaments. C. The antheridial filaments are shown at the end of the spermiogenesis. Note the mature antherozoids and lateral pores. D. Antherozoid, the region occupied by the nucleus and flagella are shown. E. Mature anteridium with shield cells with their characteristic orange colour. F. Close up of the chloroplast of mature shield cells.

ANT: antheridia; ANZ: antherozoids; CAP I: primary capitular cells; CAP II: secondary capitular cells; CES: shield cells; CL: chloroplasts; FAN: antheridial filaments; FLA: flagella; GLO: plastoglobules; INT: internodes; MAN: manubria; NOD; nodes; NUC: núcleo; POL: pore of release; TI: thylakoids. 


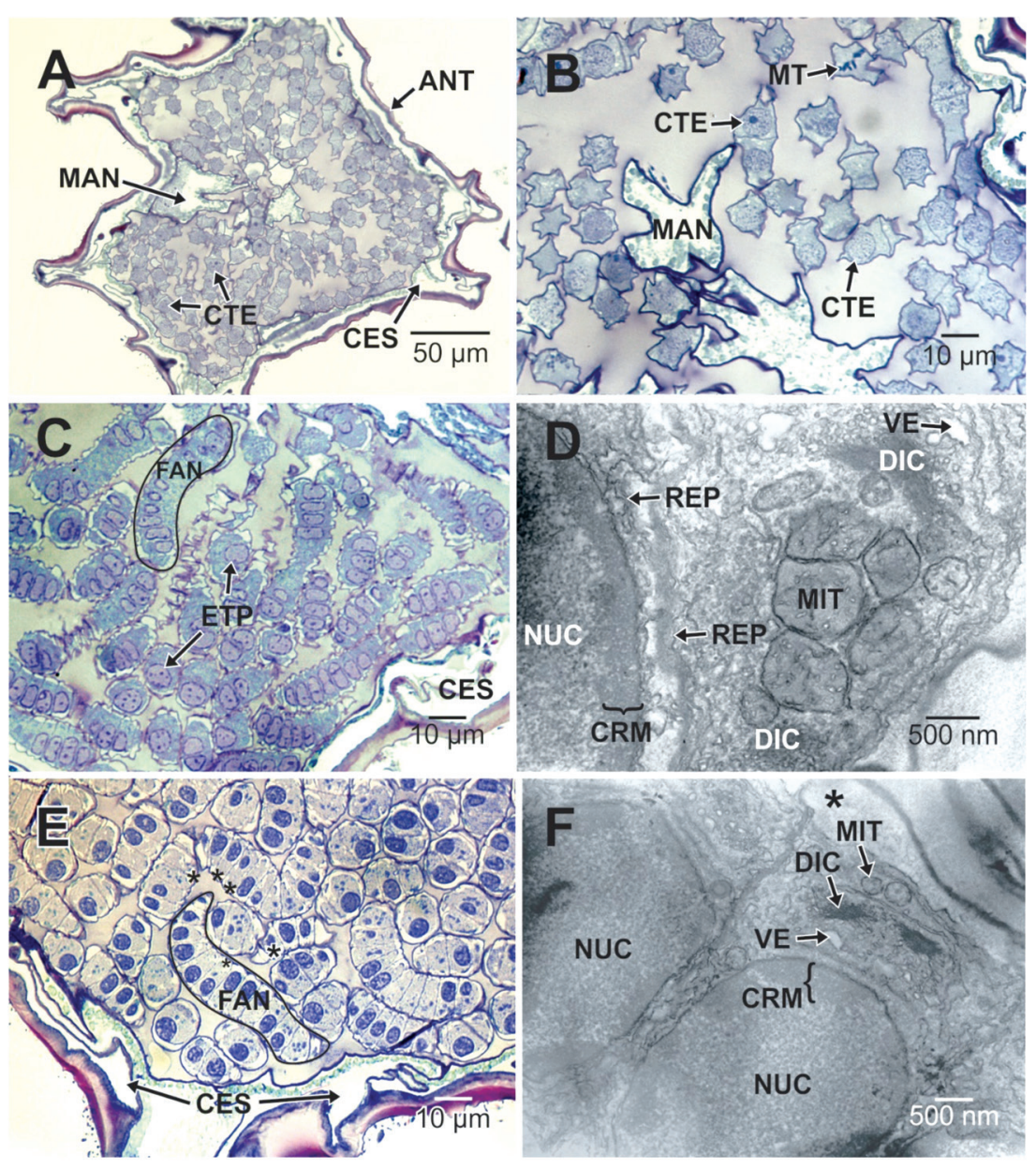

Fig. 6. A-F. Espermatogénesis y espermiogénesis de Chara hydropitys. A. Anteridios inmaduros con filamentos espermatógenos en su interior. B. Detalle de estos filamentos y las mitosis activas que los forman. C. Filamentos anteridiales con espermatocitos en su interior (resaltados en la imagen). D. Detalle de un espermatocito. Para esta etapa del desarrollo aún no se evidencia la retracción del citoplasma. E-F. Espermatocitos al inicio de la espermiogénesis en los filamentos anteridiales (resaltados en la imagen): el núcleo se aprecia más condensado y heterocromático. La retracción del citoplasma es indicada con asteriscos.

ANT: Anteridio; CES: células escuderas; CRM: cromatina condensada; CTE: Células del tejido espematógeno; DIC: dictiosomas; ETP: spermatocitos; FAN: filamentos anteridiales; NUC: núcleo; MAN: manubrio; MIT: mitocondrias; MT: mitosis; REP: retículo endoplasmático; VE: vesículas.

Fig. 6. A-F. Spermatogenesis and spermiogenesis of Chara hydropitys. A. Immature antheridia showing spermatogeneous filaments. B. Details of the active mitosis in spermatogeneous filaments. C. Antheridial filaments with spermatocytes inside (highlighted in the image). D. Close up of spermatocyte. For this development stage, there is not evident of cytoplasm retraction. E-F. Antheridial filaments showing the spermatocytes at the beginning of spermiogenesis (highlighted in the image), note that the nucleus is more condensed and heterochromatic. The cytoplasm retraction is indicated by asterisks.

ANT: Antheridium; CES: shield cells; CRM: condensed chromatin; CTE: spermatogenous tissue cells; DIC: dictyosomes; ETP: spermatocytes; FAN: antheridial filaments; NUC: nucleus; MAN: manubria; MIT: mitochondria; MT: mitoses; REP: endoplasmic reticulum; VE: vesicles. 
son más largas que anchas. El núcleo está en posición excéntrica sin nucléolos y la cromatina inicia la condensación en la periferia del núcleo (Fig. 6C). A medida que la espermiogénesis progresa, la cromatina continúa con el proceso de condensación y en el citoplasma hay un desarrollo profuso del retículo endoplasmático y se aprecian gran cantidad de ribosomas, dictiosomas y numerosas mitocondrias con abundantes crestas tubulares (Fig. 6D). Posteriormente, el citoplasma inicia la retracción que es patente en las paredes laterales y luego progresa hacia las trasversales (Fig. $6 \mathrm{E})$. En el núcleo, prosigue la condensación de la cromatina, y en el citoplasma, se aprecian dictiosomas con cisternas electrodensas y gran cantidad de vesículas asociadas (Fig. 6F).

A medida que el espermatocito se diferencia, el citoplasma se retrae dramáticamente tanto en las paredes laterales como en las transversales (Fig. 7A y Fig. 7B). En este momento del desarrollo son visibles los flagelos en diferentes planos de corte y en el citoplasma se observan algunos dictiosomas y mitocondrias, mientras que el retículo endoplasmático se torna escaso (Fig. 7B). Con la retracción del citoplasma, el gameto se va plegando a medida que el núcleo se estrecha y las raíces microtúbulares se alinean en torno a este, a las mitocondrias y a los plastidios (Fig. 7C y Fig. 7E). En esta etapa del desarrollo, en la región anterior de los gametos se observan abundantes cuerpos mieloides y gránulos de almidón de contorno hexagonal, mientras que la cromatina condensada tiene un aspecto fibroso (Fig. 7D y Fig. 7E). Además, se logra apreciar que las raíces microtubulares rodean completamente a las mitocondrias (Fig. 7D y Fig. 7E), y en la superficie de los flagelos se observaron estructuras electrodensas que corresponden a escamas de contorno romboédrico (Fig. 7E imagen del recuadro). Para el final de la espermiogénesis el citoplasma se ha retraído por completo y tanto el núcleo como las mitocondrias y los plastidios del anterozoide están en estrecho contacto con las raíces microtubulares (Fig. 7F y Fig. 7H). Así mismo, el núcleo ha alcanzado el máximo grado de condensación, y en la pared lateral de los filamentos anteridiales se observa una papila asociada a material electrodenso; ésta papila formará un poro por donde emergerá el anterozoide maduro (Fig. 7F y Fig. 7H).

\section{DISCUSIÓN}

Meurer y Bueno (2012) describieron las características morfológicas y reproductivas de especímenes de $C$. hydropitys encontrados en Brasil. En resumen, los autores describieron la sexualidad de los talos, el cortex triplóstico, las corticaciones irregulares y no presentes en todas las ramas. Dichos autores también describieron la longitud y el diámetro de los oosporangios maduros $(716-837 \mu \mathrm{m} ; 450-566$ $\mu \mathrm{m})$ y de la oóspora madura (700 y $300 \mu \mathrm{m})$. Observaron que las células espirales forman entre 11-12 circunvoluciones y los anteridios son globulares con ocho células escuderas. Los caracteres descritos por estos autores concuerdan con los observados en los especímenes de C. hydropitys recolectados de en el Departamento del Valle de Cauca-Colombia, lo que implica una mayor certeza en la identificación de esta especie y a su vez se amplía la distribución conocida para este taxón en Suramérica.

Son escasos los trabajos que describan los detalles ontogenéticos, estructurales y ultraestructurales de los oosporangios de Charophyceae hasta antes de la fecundación de la oospora, y solo se han restringido a Chara fibrosa, C. globularis Thuiller, C. hispida L., Nitella opaca (C. Agardh ex Bruzelius) C. Agardh y Lamprothamnium papulosum (K.Wallroth) J. Groves (Pickett-Heaps, 1975; Leitch, 1986; Leitch et al., 1990). Según estos autores, la oóspora de Charophyceae previo a la fecundación, solo está protegida por dos paredes celulares que corresponden a la pared primaria de la oóspora y la pared primaria de las células espirales, y solo hasta después de la fecundación, inicia el depósito de la POC simultáneamente a partir de estas dos células. Estas características del desarrollo de la pared de la oóspora se confirmaron para C. hydropitys.

Los caracteres observados por Leitch (1986) y Leitch et al., (1990) sobre la ontogenia 


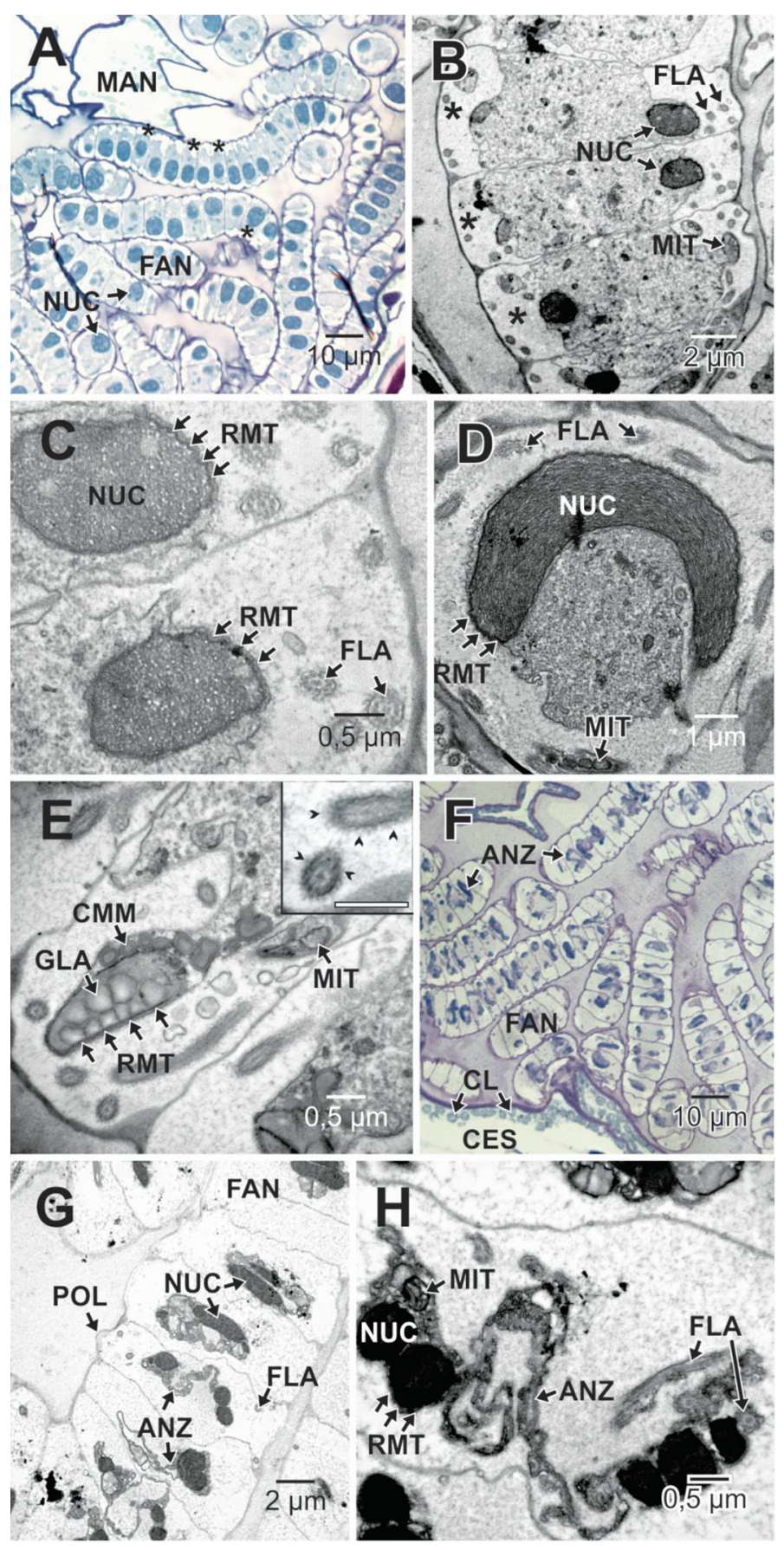

Fig. 7. A-H. Espermatogénesis y ontogenia de los anterozoides de Chara hydropitys. A-B. Espermatocitos con mayor retracción del citoplasma indicada con asteriscos. C-E. Se muestra el plegamiento del gameto en torno al núcleo, orgánulos y las raíces microtubulares. E. En el recuadro se aprecia el detalle de los flagelos y las escamas que los recubren, en corte trasversal y sagital (cabezas de flecha, escala $=0.5 \mu \mathrm{m}$ ). F-H. Anterozoides al interior de los filamentos anteridiales. G-H. Se muestran el poro de liberación, el núcleo y los orgánulos asociados a las raíces microtubulares.

ANZ: anterozoides; CES: células escuderas; CL: cloroplastos; CMM: cuerpos mieloides; FAN: filamentos anteridiales; FLA: flagelos; GLA: gránulos de almidón: NUC: núcleo; MAN: manubrios; MIT: mitocondrias; POL: poro de liberación; RMT: raíces microtúbulares.

Fig. 7. A-H. Spermatogenesis and ontogeny of the antherozoids in Chara hydropitys. A-B. Spermatocytes with major retraction of cytoplasm indicated by asterisks. C-E. Close up of gametes showing their folding around the nucleus, organelles and microtubular roots. E. Details of flagella and its scales in cross and sagittal section are shown in the box (arrowheads, scale $=0.5 \mu \mathrm{m}$ ). F-H. Antheridial filaments showing antherozoids. G-H. Release pore, note the nucleus and organelles associated to microtubular roots.

ANZ: antherozoids; CES: shield cells; CL: chloroplasts; MMC: myeloid bodies; FAN: antheridial filaments; FLA: flagella; GLA: starch granules: NUC: nucleus; MAN: manubria; MIT: mitochondria; POL: pore of release; RMT: microtubular roots. 
de oosporangio son similares a lo observado aquí para $C$. hydropitys y son caracteres constantes tanto en la subfamilia Chareae como en la sección Rothia del género Tolypella (subfamilia Nitelleae). Además, tales características en $C$. hydropitys son similares a lo observado para otras especies de Charophyceae (Pickett-Heaps, 1975; Leitch, 1986; Leitch et al., 1990). Para C. hydropitys se encontraron algunos caracteres disimiles, por ejemplo, en los especímenes estudiados por Leitch (1986) se detectaron plastoglóbulos en las células espirales. Mientras que, en los especímenes de esta investigación, los plastoglóbulos están únicamente restringidos a los cloroplastos de las células escuderas de los anteridios maduros. De igual forma Leitch (1986) registró la presencia de vacuolas en las células madre de la oóspora y en las oósporas jóvenes, situación que no se observó en $C$. hydropitys.

Los detalles ultraestructurales observados con MET, tales como la electrodensidad, textura y origen de las ocho capas de la POC madura de $C$. hydropitys son similares a lo descrito para otras especies de Chara y Lamprothamnium y representan caracteres conservados en las especies de estos géneros (Leitch, 1986, 1989; Leitch et al., 1990). No obstante, para poder soportar esta idea sería necesario ampliar este tipo de trabajos a un número representativo de especies en ambos géneros.

Por otro lado, Leitch (1986) encontró que en Nitella opaca la capa cristalina de la POC está ausente, y en su lugar se encuentra una zona de tres capas de material orgánico, lo cual es claramente diferente con lo observado en las especies del género Chara. Sin embargo, es de aclarar que no se conocen trabajos adicionales de la POC con MET para Nitella $\mathrm{u}$ otras especies de Charophyceae diferentes a Chara o Lamprothamnium. Esta situación es contrastante, ya que varios autores han sugerido la importancia taxonómica de la ultraestructura de la POC (Cáceres, 1977; Leitch, 1989; Leitch et al., 1990).

Leitch (1986) detalla los rasgos ultraestructurales de las paredes anticlinales y periclinales de las células espirales de los oosporangios maduros de Chara y Lamprothamnium. En sus observaciones encontró que la pared anticlinal externa es gruesa y presenta apariencia multilaminar, en tanto que la anticlinal interna y las periclinales son homogéneas y delgadas. Estos caracteres coinciden, en general, con lo observado en $C$. hydropitys de la presente investigación. Sin embargo, en los especímenes analizados las paredes periclinales de las células espirales maduras, presentan un engrosamiento que se extiende sobre el borde espiral, y que corresponde a la proyección de la microornamentación presente en la zona de la fosa, lo cual coincide con lo mencionado por John et al., (1990) y Krishnan (2006).

Sakayama et al., (2005) y Sakayama (2008) describen con MEB la morfología interna de la POC fracturada en varias especies del género Nitella identificando tres patrones morfológicos: el homogéneo, el débilmente esponjoso y el fuertemente esponjoso. Sin embargo, aunque hay una diferenciación morfológica, estas observaciones no son comparables con las realizadas con MET. Dada esta situación, sería interesante determinar si los tres tipos de morfológicos descritos para Nitella con MEB son similares en las especies de los géneros Chara, Lamprothamnium, Nitellopsis (N. A. Desvaux) J. Groves, Tolypella (A. Braun) A. Braun y Lychnothamnus (Ruprecht) A. Braun. Esta información sería relevante puesto que los patrones morfológicos internos de la POC obtenidos con MEB han mostrado ser importantes filogenéticamente, y estos caracteres son útiles en taxonomía, incluso a nivel especifico, al menos para el género Nitella (Sakayama et al., 2005; Sakayama, 2008).

Leitch et al. (1990) y Leitch $(1986 ; 1991)$ determinaron que para algunas especies como Chara delicatula C. Agardh, nom. illeg., C. hispida y L. papulosum el depósito de la capa calcificada se da al final de la formación de la POC. Según estos mismos autores la capa calcificada se deposita progresivamente sobre las paredes anticlinales internas y avanza sobre las periclinales de las células espirales con lo cual el depósito de la capa calcificada en perfil se aprecia de forma cóncava o en forma 
de "U" y a medida que se va engrosando adquiere forma convexa. Estas observaciones concuerdan con lo observado para $C$. hydropitys, y tal vez representan caracteres conservados para las especies de Chara y Lamprothamnium. No obstante, esta cuestión solo podrá ser resuelta hasta que se hagan análisis estructurales y ultraestructurales detallados en las especies de esto dos géneros.

La presencia de endocalcina y ectocalcina en la capa calcificada, así como sus características de electrodensidad y presencia o ausencia de microgránulos electrodensos respectivamente, se confirman para $C$. hydropitys y es similar a lo registrado para otras especies de Chara y Lamprothamnium Leitch (1991). Aunque los límites entre estas dos estructuras no son tan evidentes, aún con MET. Cabe aclarar que al igual que en las investigaciones de Leitch et al. (1990) y Leitch (1991), las técnicas de contraste con acetato de uranilo y citrato de plomo que se utilizaron en la preparación de las muestras para contrastar la matriz orgánica que sostiene a la capa calcificada, pudieron afectar la diferenciación de estas dos capas por descalcificación.

La estructura y microornamentación de la pared de la oóspora madura de C. hydropitys son congruentes con las observaciones hechas por John et al. (1990) y Krishnan (2006). Estos autores indican que para la circunscripción específica de $C$. hydropitys son fundamentales las características ultraestructurales de la ornamentación de la zona de la fosa. Estas parecen ser constantes y están poco influenciadas por factores ambientales. No obstante, tal y como se verificó en este trabajo, $C$. hydropitys puede presentar variaciones en algunos caracteres de la oóspora, como el tamaño, el número de circunvoluciones y la cantidad de papilas que atraviesan la zona de la fosa, tales variaciones también fueron observadas por John et al. (1990) y Krishnan (2006).

La estructura de los anteridios maduros del género Chara fueron detallados por PickettHeaps (1968) quien los describe como estructuras globulares que se desarrollan en los nodos vegetativos del alga y que están protegidos por un grupo de ocho células escuderas, y en su interior se encuentran las células del manubrio y las del capítulo primario y secundario. Este autor también determinó que las células del capítulo secundario se dividen de manera activa por mitosis para formar las células espermatógenas. Estos eventos de crecimiento y diferenciación son similares a los observados en $C$. hydropitys y son congruentes con las observaciones hechas en otras investigaciones (Kwiatkowska \& Maszewski, 1986; Lee, 2008; Domozych, Sørensen, \& Willats, 2009).

El color naranja brillante observado en los anteridios maduros de $C$. hydropitys puede deberse a la presencia de los plastoglóbulos, ubicados entre las laminillas tilacoidales de los cloroplastos de las células escuderas. De acuerdo con las observaciones de esta investigación, los plastoglóbulos almacenan grandes cantidades de pigmentos carotenoides responsables de dicha coloración. Estas apreciaciones concuerdan con los trabajos realizados por varios autores para otras especies de Chara (PickettHeaps, 1968; Lee, 2008; Domozych et al., 2009). Así mismo, Schagerl y Pichler (2000) utilizando cromatografía liquida de alta eficiencia, detectaron la presencia de varios tipos de carotenoides en los anteridios maduros de Chara tomentosa L. Estos hallazgos soportan la presencia de plastoglóbulos con carotenoides en los anteridios de C. hydropitys.

Estudios en plantas han demostrado que los plastoglóbulos no solo almacenan pigmentos, sino también están relacionados con diferentes rutas metabólicas, en especial las relacionadas con la producción de compuestos antioxidantes como los tocoferoles (Vidi et al., 2006; Bréhélin, Kessler, \& van Wijk, 2007; Egea et al., 2010). Tanto los carotenoides como los tocoferoles son compuestos que se generan en respuesta al estrés oxidativo que podría causar fotoinhibición y daños en el fotosistema II. En contraste, en las algas se ha demostrado la importancia de los plastoglóbulos y sus carotenoides como mecanismos de respuesta al estrés hídrico y lumínico, en especial ante la radiación ultravioleta (Holzinger \& Lütz, 2006; Holzinger \& Karsten, 2013). Lohscheider y Bártulos 
(2016) identificaron en varios taxones de algas secuencias homólogas de las proteínas $F N B$ (Fibrilinas) y $A B C 1 K$, las cuales son dos de los principales componentes de los plastoglóbulos encontrados en plantas, y que se relacionan al parecer con la producción de pigmentos y diferentes respuestas al estrés por factores bióticos y abióticos. Teniendo en cuenta toda la información anterior, es lógico pensar que los plastoglóbulos cargados con pigmentos carotenoides en $C$. hydropitys, podrían actuar como agentes protectores que evitarían el estrés oxidativo en los filamentos anteridiales, durante los procesos de formación y diferenciación de los anterozoides.

Vouilloud et al. (2012) indicaron que para la formación de los anterozoides de C. contraria var. nitelloides a partir de las células espermatógenas, se dan una serie de eventos estructurales y subcelulares en la ontogenia, que llevan a la formación, diferenciación y liberación de los anterozoides biflagelados. En este orden de ideas los autores determinaron la presencia de los siguientes estadios: etapa precentriolar, etapa centriolar, etapa de elongación, etapa de plegamiento del gameto, etapa de diferenciación de los flagelos y por último la dispersión de los anterozoides. En gran medida, los eventos de la espermatogénesis y posterior espermiogénesis descritos por estos autores, se pudieron constatar en este trabajo para $C$. hydropitys y corresponden también con las etapas descritas para otras especies de Chara (Pickett-Heaps, 1968; Cocucci \& Cáceres, 1976; Robert, 1979; Duncan et al., 1997; Vouilloud et al., 2010, 2012) y de Nitella (Turner, 1968).

Para $C$. hydropitys, además se registra la presencia de estructuras multimembranosas denominadas cuerpos mieloides. Estos fueron observados al final de la espermiogénesis y su presencia coincide con la fuerte retracción y pérdida del citoplasma, que se da a medida que se diferencian los gametos, tal y como lo proponen Pickett-Heaps (1968) y Vouilloud et al. (2012). Así mismo, hay una región de los anterozoides maduros de C. hydropitys donde se pueden ver asociados mitocondrias y plastidios, y zonas donde se ubican solo mitocondrias, que están completamente rodeadas por las raíces microtubulares. Estas características ultraestructurales al parecer son comunes para las especies de Chara (Pickett-Heaps, 1968; Cocucci \& Cáceres, 1976; Robert, 1979; Vouilloud et al., 2010, 2012), pero no para los anterozoides de las especies de Nitella (Turner, 1968; Vouilloud et al., 2010).

En $C$. hydropitys no necesariamente fueron observados todos los eventos subcelulares que caracterizan a un determinado estadio del desarrollo de los anterozoides. Tal es el caso de los centriolos y cuerpos basales que no fueron fácilmente distinguibles, probablemente por su alta electrodensidad que dificultó su visualización e ilustración. Para finalizar, y teniendo en cuenta lo anterior se puede indicar que los eventos ontogéneticos y de diferenciación de los gametos masculinos en Charophyceae, en un sentido amplio, representan una característica muy conservada en este grupo de organismos. No obstante, también se observaron detalles ultraestructurales que al parecer son característicos del género Chara.

\section{AGRADECIMIENTOS}

Los autores agradecemos a las siguientes Instituciones y personas: Instituto de Biología de la Universidad de Antioquia (UdeA-Laboratorio de Botánica), Laboratorio de Microscopía Electrónica de Barrido de la Escuela de Materiales, Universidad del Valle (UNIVALLE), Unidad de Microscopía Electrónica de la Universidad del Cauca (UNICAUCA), Unidad de Microscopía Electrónica de la Universidad Nacional de Colombia, Sede Palmira (UNAL), A Norma Catarina Bueno (Universidade Estadual do Oeste do Paraná, Brasil) por las asesorías en la circunscripción especifica del material y Patricia Leonardi (Universidad Nacional del Sur, Departamento de Biología, Bioquímica y Farmacia, Argentina) por sus comentarios y envío de material bibliográfico. 


\section{RESUMEN}

Los oosporangios y anteridios de Charophyceae son los órganos de reproducción sexual femeninos y masculinos respectivamente. Estas estructuras se caracterizan por su complejidad morfológica y utilidad en taxonomía y sistemática. En el presente trabajo se describen los detalles estructurales y ultraestructurales de la gametogénesis en Chara hydropitys. El material fértil del alga se recolectó en una quebrada tributaria del Río Meléndez en la ciudad de Cali, Colombia ( $\left.3^{\circ} 21^{\prime} 23^{\prime \prime} \mathrm{N}-76^{\circ} 32^{\prime} 5.2^{\prime \prime} \mathrm{W}\right)$. Los especímenes fueron fijados y procesados de acuerdo a los protocolos estándar para la inclusión en resina y obtención de secciones finas que se colorearon con toluidina $\mathrm{O}$ (0.3-0.7 $\mu \mathrm{m})$ para su observación en microscopía fotónica y secciones ultrafinas $(60-90 \mathrm{~nm})$ para microscopía electrónica de transmisión (MET). Además, se procesaron muestras para microscopio electrónico de barrido (MEB). Los oosporangios están recubiertos por las células espirales que forman de 10-12 circunvoluciones y terminan en cinco células coronulares. La pared de los oosporangios inmaduros está formada por dos capas que corresponden a la pared de las células espirales y de la oosfera. Al madurar la pared del oosporangio tiene seis capas adicionales, tres de las cuales son aportadas por la oospora y las tres restantes por las células espirales. La oosfera aumenta progresivamente de tamaño a medida que las células espirales crecen y se dividen. En el citoplasma de la oosfera inmadura no se aprecian inclusiones citoplasmáticas conspicuas, pero con la maduración el número de gránulos de almidón aumenta llegando a ocupar la mayor parte del volumen celular. En las células espirales del oosporangio maduro se observan numerosos cloroplastos con prominentes depósitos de almidón entre las lamelas tilacoidales y una vacuola que ocupa casi toda la célula. En las observaciones con MEB se aprecia que la pared externa de la oospora, sobre la zona de la fosa presenta microornamentaciones de tipo verrucado. En los anteridios maduros las células del escudo están fuertemente pigmentadas de color naranja por la presencia de numerosos plastoglóbulos entre las lamelas tilacoidales. De las células del capítulo secundario se desarrollan los filamentos espermatógenos que por divisiones mitóticas unidireccionales y sincrónicas forman los espermatocitos. A partir de estas células haploides por espermiogénesis se desarrollarán los anterozoides biflagelados. Los eventos subcelulares relacionados con estos procesos de división y diferenciación celular incluyen inicialmente cambios en la condensación de la cromatina, pérdida del nucléolo y mayor actividad de los dictiosomas. Posteriormente, el citoplasma se retrae y los orgánulos se alinean a lo largo del núcleo condensado y del aparato flagelar. Los anterozoides maduros emergen a través de un poro lateral de la pared de los espermatocitos. Todos los eventos descritos indican que los procesos de gametogénesis y los detalles estructurales de los gametos son por lo general características ampliamente conservadas en este grupo de algas.
Palabras clave: anteridio, Chara, gametogenesis, oosporangio, pared oosporangial compuesta, ultraestructura.

\section{REFERENCIAS}

Arora, M., \& Sahoo, D. (2015). Growth forms and life histories in green algae. In D. Sahoo \& J. Seckbach (Eds.), The Algae World, Cellular Origin, Life in Extreme Habitats and Astrobiology (vol. 26) (pp. 121-175). Delhi, India: Springer Netherlands.

Beilby, M. J., \& Casanova, M. T. (2014). The physiology of characean cells. Berlin, Germany: Springer-Verlag.

Blume, M., Blindow, I., Dahlke, S., \& Vedder, F. (2009). Oospore variation in closely related Chara taxa. Journal Phycology, 45, 995-1002.

Bozzola, J. J, \& Russell, L. D (1998). Electron microscopy: principles and techniques for Biologists (2nd ed.). London, England: Jones and Bartlett Publishers.

Bréhélin, C., Kessler, F., \& van Wijk, K. J. (2007). Plastoglobules: versatile lipoprotein particles in plastids. TRENDS in Plant Science, 12(6), 260-266.

Bueno, N., Bicudo, C. E. M., Biolo, E., \& Meurer, T. (2009). Levantamento florístico das Characeae (Chlorophyta) de Mato Grosso e Mato Grosso do Sul, Brasil: Chara. Revista Brasileira de Botânica, 32(4), 759-774.

Bueno, N., Prado, J., Meurer, T., \& Bicudo, C. E. M. (2011). New records of Chara (Chlorophyta, Characeae) for subtropical southern Brazil. Systematic Botany, 36(3), 523-541.

Casanova, M. (1991). An SEM study of developmental variation in oospore wall ornamentation of three Nitella species (Charophyta) in Australia. Phycologia, 30(3), 237-242.

Casanova, M. (1997). Oospore variation in three species of Chara (Charales, Chlorophyta). Phycologia, 36(4), 274-280.

Cáceres, E. J. (1977). Precisiones sobre la ornamentación de la oóspora de Nitella megacarpa. Kurtziana, $10,250-1$.

Cirujano, S., Murillo, P., Meco, A., \& Fernández, R. (2007). Los Carófitos Ibéricos. Anales del Jardín Botánico de Madrid, 64(1), 87-102.

Cocucci, A. E., \& Cáceres, E. J. (1976). The ultrastructure of the male gametogenesis in Chara contraria var. nitelloides (Charophyta). Phytomorphology, 30, 5-16.

Coops, H. (2002). Ecology of charophytes: an introduction. Aquatic Botany, 72, 205-208. 
De Winton, M., Dugdale, T., \& Clayton, J. (2007). An identification key for oospores of the extant charophytas of New Zealand. New Zealand Journal of Botany, $45,463-476$.

Domozych, D., Sørensen, I., \& Willats, G. (2009). The distribution of cell wall polymers during antheridium development and spermatogenesis in the Charophycean green algae, Chara corallina. Annals of Botany, 104, 1045-1056.

Duncan, T. M., Renzaglia, K. S., \& Garbary, D. J. (1997). Ultrastructure and phylogeny of the spermatozoid of Chara vulgaris (Charophyceae). Plant Systematics and Evolution, 204, 125-140.

Egea, I., Barsan, C., Bian, W., Purgatto, E., Latché, A., Chervin, C., Bouzayen, M., \& Pech, J. C. (2010). Chromoplast differentiation: current status and perspectives. Plant \& Cell Physiology, 51(10), 1601-1611.

Graham, J., Wilcox, L., \& Graham, L. (2009). Algae (2 $2^{\text {nd }}$ ed.). London, England: Prentice Hall.

Haas, J. (1994). First identification key for charophyte oospore from central Europe. European Journal of Phycology, 29(4), 227-235.

Holzinger, A., \& Lütz, C. (2006). Algae and UV irradiation: effects on ultrastructure and related metabolic functions. Micron, 37, 190-207.

Holzinger, A., \& Karsten, U. (2013). Desiccation stress and tolerance in Green algae: consequences for ultrastructure, physiological, and molecular mechanisms. Frontiers in Plant Science, 4(327), 1-18.

John, D., \& Moore, J. (1987). An SEM study of the oospore of some Nitella species (Chlorophyta, Charales) with descriptions of wall ornamentation and an assessment of its taxonomic importance. Phycologia, $26,334-355$.

John, M. D., Moore, A. J., \& Green, D. (1990). Preliminary observations on the structure and ornamentation of oosporangial wall in Chara (Charales, Chlorophyta). Bristish Phycological Journal, 25(1), 1-24.

Kalin, M., \& Smith, M. (2007). Germination of Chara vulgaris and Nitella flexilis oospores: What are the relevant factors triggering germination? Aquatic Botany, 87(3), 235-241.

Khan, M., \& Sharma, Y. S. R. K. (1984). Cytogeography and cytosystematics of charophyta. In D.G. E. Irvine y D. M. John (Eds.), Systematics of green algae (pp. 303-330). London, England: Academic Press.

Karol, K. G., McCourt, R. M., Cimino, M. T., \& Delwiche, C. F. (2001). The closest living relatives of land plants. Science, 294, 2351-2353.

Krishnan, U. (2006). Differentiation of Chara gymnopitys A. Br. and Chara hydropitys Reich. by morphological characters, isozyme analysis and oospore wall ornamentation. Cryptogamie Algologie, 27(4), 473-490.

Kwiatkowska, M., \& Maszewski, J. (1986). Changes in the occurrence and ultrastructure of plasmodesmata in antheridia of Chara vulgaris L., during different stages of spermatogenesis. Protoplasma, 132, 179-188.

Lee, R. E. (2008). Phycology (4th ed.). New York, U.S.A: Cambridge University Press.

Leitch, A. R. (1986). Studies on living and fossil charophyte oosporangia (Ph.D. Thesis). Bristol University, England.

Leitch, A. R. (1989). Formation and ultrastructure of a complex, multilayered wall around the oospore of Chara and Lamprothamnium (Characeae). European Journal of Phycology, 24, 229-236.

Leitch, A. R. (1991). Calcification of the charophyte oosporangium. In R. Riding (Ed.), Calcareous algae and stromatolites (pp. 204-216). Berlin, Germany: Springer-Verlag Berlin Heidelberg.

Leitch, A. R., John, D., \& Moore, J. (1990). The oosporangium of the Characeae (Chlorophyta, Charales). Progress in Phycological Research, 7, 214-263.

Lemieux, C., Otis, C., \& Turmel, M. (2007). A clade uniting the green algae Mesostigma viride and Chlorokybus atmophyticus represents the deepest branch of the Streptophyta in chloroplast genome-based phylogenies. BMC Biology, 5, 2.

Lohscheider, N. J., \& Bártulos, C. R. (2016). Plastoglobules in algae: a comprehensive comparative study of the presence of major structural and functional components in complex plastids. Marine Genomics, $28,127-136$.

McCourt, R., Delwiche, C., \& Karol, K. (2004). Charophyte algae and land plant origins. Trends in Ecology and Evolution, 19(12), 661-666.

Meurer, T., \& Bueno, N. C. (2012). The genera Chara and Nitella (Chlorophyta, Characeae) in the subtropical Itaipu Reservoir, Brazil. Brazilian Journal of Botany, 35(2), 219-232.

Meurer, T., Biolo, S., Bortolini, J. C., \& Bueno, N. C. (2008). Characeae (Chlorophyta) do Reservatório de Itaipu: Chara braunii Gmelin. Revista Brasileira de Biociências, 6, 3-4.

Moestrup, Ø. (1970). The fine structure of mature spermatozoids of Chara corallina, with special reference to microtubules and scales. Planta (Berlin), 93, 295-308.

Pickett-Heaps, J. D. (1968). Ultrastructure and differentiation in Chara fibrosa. IV. Spermatogenesis. Australian Journal of Biological Sciences, 21, 655-690. 
Pickett-Heaps, J. D. (1975). Green algae: structure, reproduction and evolution in selected genera. Massachusetts, U.S.A: Sinauer Associates.

Proctor, V. (1971). Taxonomic significance of monoecism and dioecism in the genus Chara. Phycologia, 10(23), 299-303.

Ray, S., Pekkari, S., \& Snoeijs, P. (2001). Oospore dimensions and wall ornamentation patterns in Swedish charophytes. Nordic Journal of Botany, 21(2), 207-224.

Robert, D. (1979). Localization cytochimique en microscopie e'lectronique, des constituents nucle'aires au cours de la spermioge'ne chez le Chara. Annales des sciences naturelles Botanique, (Se'r. 13)1, 67-80.

Sakayama, H., Miyaji, K., Nagumo, T., Kato, M., Hara, Y., \& Nozaki, H. (2005). Taxonomic reexamination of 17 species of Nitella subgenus Tieffallenia (Charales, Charophyceae) based on internal morphology of the oospore wall and multiple DNA marker sequences. Phycology, 41(1), 195-211.

Sakayama, H. (2008). Taxonomy of Nitella (Charales, Charophyceae) based on comparative morphology of oospores and multiple DNA marker phylogeny using cultured material. Phycological Research, $56,202-215$.

Sato, M., Sakayama, H., Sato, M., Ito, M., \& Sekimoto, H (2014). Characterization of sexual reproductive processes in Chara braunii (Charales, Charophyceae). Phycological Research, 62, 214-221.

Schagerl, M., \& Pichler, C. (2000). Pigment composition of freshwater charophyceae. Aquatic Botany, $67,117-129$

Schneider, S. (2007). Macrophyte trophic indicator values from a European perspective. Limnologica, $37,281-289$

Schneider, S., Rodrigues, A., Moe, T. F., \& Ballot. A. (2015). DNA barcoding the genus Chara: molecular evidence recovers fewer taxa than the classical morphological approach. Journal of Phycology, $51,367-380$

Spurr, A. (1969). A low-viscosity epoxy resin embedding medium for Electron Microscopy. Journal Ultrastructure Research, 26, 31-43.

Timme, R. E., Bachvaroff, T. R., \& Delwiche, C. F. (2012) Broad phylogenomic sampling and the sister lineage of land plants. PloS ONE, 7(1), 1-8.
Turmel, M., Otis, C., \& Lemieux, C. (2006). The mitocondrial genome of Chara vulgaris: insights into the mitocondrial DNA architecture of the last common ancestor of green algae and land plants. Molecular Biology and Evolution, 23(6), 1324-1338.

Turner, F. R. (1968). An ultrastructural study of plant spermatogenesis. Journal of Cell Biology, 37, 370-393.

Urbaniak, J. (2011). A SEM and light microscopy study of the oospore wall ornamentation in Polish charophytes (Charales, Charophyceae)-genus Chara. Nova Hedwigia, 93(1-2), 1-28.

van den Hoek, C., Mann, D. J., \& Jahns, H. M. (1995). Algae: an Introduction to phycology. 1st Ed. London, England: Cambridge University Press.

Van Dijk, G. M., \& Van Vierssen, W. (1991). Survival of Potamogeton pectinatus population under various light conditions in a shallow eutrophic lake (Lake Veluwe) in The Netherlands. Aquatic Botany, 39, 121-130.

Vidi, P. A., Kanwischer, M., Baginsky, S., Austin, J. R., Csucs, G., Dörmann, P., Kessler, F., \& Bréhélin, C. (2006). Tocopherol cyclase (VTE1) localization and vitamin $\mathrm{E}$ accumulation in chloroplast plastoglobule lipoprotein particles. The Journal of Biological Chemistry, 281, 11225-11234.

Vouilloud, A. A., Cáceres E. J., \& Leonardi, P. I. (2010). Ultraestructure of the mature male gamete of Nitella hialina (Charales, Charophyta). Phycologia, 49(5), 508-511.

Vouilloud, A. A., Leonardi, P. I., \& Cáceres, E. J. (2012). Ultrastructure of male gametogenesis in Chara contraria var. nitelloides (Charales, Charophyta) revisited: a model for a better characterization of the process in Charales. Phycologia, 51(3), 239-246.

Wodniok, S., Brinkmann, H., Glockner., G., Heidel. A. J., Philippe, H., Melkonian, M., \& Becker, B. 2011. Origin of land plants: do conjugating green algae hold the key? BMC Evolutionary Biology, 11(104), 1-10.

Wood, R. (1964). A synopsis of the Characeae. Bulletin of the Torrey Botanical Club, 91(1), 35-46.

Wood, R. (1965). Monograph of the Characeae (vol.1). In R. Wood \& K. Imahori (Eds.), A Revision of the Characeae (pp. 1-904). Weinheim: J. Cramer.

Wood, R. D., \& Imahori, K. (1965). A Revision of the Characeae. First Part: Monograph of the Characeae. Weinheim: J. Cramer. 